\title{
Editorial
}

\section{The Patient's Call Versus the Patient's Well Being}

\section{A. A. Mamun Hussain ${ }^{1}$}

In the early part of last century health was considered as a life, lived in the silence of the organs, when medicine was considered as the discipline that produces doctors who respond to their patient's call and this call is "Pathetic" (i.e. Linked to suffering). In 1946, $\mathrm{WHO}^{1}$ proposed a radically different perspective: "Health is a state of complete physical, mental and social wellbeing and not merely the absence of disease or infirmity. In $1985, \mathrm{WHO}^{2}$ proposed further clarification on its definition of health: "To reach a state of complete physical, mental, and social wellbeing, an individual or group must be able to identify and to realize aspirations, to satisfy needs, and to change or cope with the environment”.

In recent years, new information from the fields of neuroscience and behavioral medicine has dramatically advanced our understanding of mental functioning. Increasingly, it is becoming clear that mental functioning has a physiological underpinning, and is fundamentally interconnected with physical and social functioning and health outcomes.

Across the centuries ${ }^{3}$, physicians, scientist, and mental health professionals have progressively identified diseases and disorders from pattern of symptoms and biological abnormalities. Physicians are so fascinated by disease that with time, medicine has become the discipline that diagnoses and treat disease instead of the discipline that treats patient. So there is a gap today between the expectation of society concerning medicine, and what is offered by physicians in general and psychiatrists in particular. Because of this gap, new concepts like health, mental health, happiness and positive psychology have been introduced to challenge the powerful and well established field of medicine.

Although the question of happiness raises numerous perspective and theories, the total wellbeing is studied by different researchers. The $\mathrm{UNESCO}^{4}$, considering five dimensions, viz. material well being, health and safety, education, behaviors and risks, and housing and environment, studied child wellbeing in 29 rich countries including the USA, Canada and 27 European nations.

It was observed that

- The Netherlands and most Scandinavian countries are the top ranking countries.

- The Baltic countries, Greece, Romania, and the USA are the lowest ranking countries.

- The relationship between per capita GDP and overall child wellbeing is not clear. Indeed, the Czech Republic is ranked higher than Austria, Slovenia higher than Canada, and Portugal higher than USA.

Seligman $^{5}$, considering these issues, made an important contribution by formulating the concept of positive psychology, which is in fact, a scientific study of positive human functioning and flourishing on multiple levels that include the biological, personal, relational, institutional, cultural and global dimensions of life. As the object of medicine and psychiatry is distress in human being, today the great maestros of medical domain are emphasizing two urgent needs, viz.- 
caring for the patient instead of being obsessed with disorders, and investing more in prevention. Now then, considering all these discussions, it is evident that there is ample room left for the health professional of the millennium who wishes to develop the notion of well-being instead of simply dealing with "ill-being".

\section{References:}

1. WHO. The Ottawa Charter for Health Promotion. (July 20, 2015). Retrieved July 20,2015, from:http://www.who.int/healthpromotion/conferenc es/previous/ottwa/en/.

2. WHO. The World Health Report 2001-Mental Health: New Understanding, New Hope. (July 21, 2015). Retrieved July 21, 2015, from: http:// www.who.int.whr.2001/en/.
3. Sin, N.L, \& Lyubomirsky, S. (2009). Enhancing wellbeing and alleviating depressive symptoms with positive psychology interventions: a practicefriendly meta-analysis. Journal of Clinical Psychology, 65 (5), 467-487. http:// dx. doi. org/ 10.1002/jclp.20593.

4. Falissard B. Positive Mental Health-What is it, How is it Recognized, and can it be achieved? In Positive Mental Health, fighting stigma and promoting Resiliency. Editors. Hodes M, Gauos. Elsevier 2016.

5. Seligman, M. E. P. \& Csikszentmihalyi, M. (2000). Positive psychology: an introduction. American Psychologist, 55 (1), 5-14. http:// dx. doi. org/ 10.1037/ 0003-066X.55.1.5.

All correspondence to: Prof. A. A. Mamun Hussain Professor Department of Psychiatry Rajshahi Medical College, Rajshahi. Email: sh017866@gmail.com 